\title{
Identification of Ubiquitin System Factors in Growth Hormone Receptor Transport
}

\author{
Johan A. Slotman, Peter van Kerkhof, \\ Gerco Hassink, Hendrik J. Kuiken and Ger J. Strous
}

Additional information is available at the end of the chapter

http://dx.doi.org/10.5772/46058

\section{Introduction}

Proteins can be covalently modified by ubiquitin. These modifications are the result of a coordinated enzymatic process and regulate many cellular networks and processes (Schwartz \& Ciechanover, 2009, Weissman et al., 2011). First, ubiquitin is activated by an ubiquitin activating enzyme (E1), then the activated ubiquitin is transferred to the active cysteine of an ubiquitin conjugating enzyme (E2), which interacts with a substrate recognizing enzyme, the ubiquitin ligating enzyme (E3). This enzyme positions ubiquitin towards the substrate, after which ubiquitin is covalently linked via its C-terminal glycine residue to the $\varepsilon$-amino group of a lysine residue. The human genome contains two E1, $35 \mathrm{E} 2$, and more than 1000 E3 enzymes. The E3s are subdivided in three types: Hect, Ring and Ubox domain containing. Ubiquitin has seven internal lysine residues that can be modified with ubiquitin, resulting into chains of multiple ubiquitin moieties. Depending on the internal lysine that is modified, different types of ubiquitin chains can be synthesized. The most abundant ubiquitin chains are linked via lysine-48 (K48), lysine-63 (K63), or combinations, resulting in mixed chains (Goto et al., 2010). Additionally, it was recently discovered that linear ubiquitin chains are important in $\mathrm{NF \kappa B}$ activation. These chains are formed by LUBAC ("linear ubiquitin chain-assembly complex"), by conjugating ubiquitin moieties head-to-tail (Iwai K \& Tokunaga, 2009, Rahighi et al., 2009). Substrates can be modified by one ubiquitin moiety (mono-ubiquitylation), by one ubiquitin moiety on more than one lysine in the same substrate (multiple mono-ubiquitylation) or by chains of ubiquitin (poly-ubiquitylation). Analogous to phosphorylation, ubiquitin can be removed from substrates. A special class of proteases, the deubiquitylating enzymes (DUBs) of which there are approximately 100 genes in the human genome, can specifically remove ubiquitin moieties (reviewed in Soboleva \& Baker, 2004). Modification by ubiquitin can have several outcomes for a substrate protein. Besides degradation by the proteasome, ubiquitin 
modification can regulate a.o. DNA repair as well as sorting of transmembrane proteins, which is the topic of this chapter. Clathrin mediated endocytosis, a well characterized mode of endocytosis of membrane and cargo molecules, involves the recognition of cargo, assembly of the coat and the pinching off of the invagination (Marsh \& McMahon, 1999). The cargo is acquired by adapter proteins such as AP-2 or by AP-2 binding proteins such as Epsin1 or Eps15, after which the clathrin lattice is formed and the membrane is curved by BAR domain-containing proteins (Kirchhausen, 1999). The curved domain is pinched off by dynamin and forms a cargo-containing coated vesicle. Subsequently, this vesicle is uncoated and fused with early endosomes (van der Bliek et al., 1993). From the early endosomes the cargo can either be transported toward the lysosome, ultimately resulting in degradation, or recycled back to the plasma membrane. These decisions are mediated by three endosomal sorting complexes, ESCRT-I, -II and -III (Jovic et al., 2010).

The involvement of ubiquitin in membrane traffic was first described in yeast, where ubiquitylation of both the $\alpha$-factor receptor and carboxypeptidase S by the HECT E3 ligase Rsp5 is essential for endocytosis as well as for their correct trafficking into the multi vesicular bodies (MVB) (Hicke \& Riezman, 1996). In mammalian cells, the role of ubiquitin was first studied for the growth hormone $(\mathrm{GH})$ receptor and the sodium channel $\mathrm{ENaC}$ (Staub et al., 1996, Strous et al., 1996). ENaC is ubiquitylated by the HECT E3 Nedd4-2 and is subsequently recognized by the ubiquitin binding domain containing clathrin adapter Epsin1. After endocytosis, deubiquitylation of ENaC by the DUBs UHC-L3 and USP2 determines its fate at the multivesicular bodies. $\mathrm{ENaC}$ that remains ubiquitylated is recognized by the ESCRT complexes and degraded in the lysosome, whereas deubiquitylated $\mathrm{ENaC}$ is recycled back toward the plasma membrane (Butterworth \& Johnson, 2008). A second DUB involved in ENaC down regulation is USP10, which can deubiquitylate sorting nexin 3, resulting in both decreased ENaC endocytosis and increased recycling. USP10 is also implied in endocytosis and recycling of the cystic fibrosis transmembrane conductance regulator CFTR (Bomberger et al., 2010, Boulkroun et al., 2008).

The role of ubiquitylation in endocytosis of receptor tyrosine kinases has been extensively studied for the tyrosine kinase receptor, the epidermal growth factor (EGF) receptor. The RING E3 ligase c-Cbl and the E2 enzyme Ube2D1-4 are involved in ubiquitylation of the EGF receptor. Its clathrin-dependent endocytosis is regulated via binding to the clathrin adapter AP-2, either directly or via the ubiquitin binding endocytosis adapter Eps15 or Epsin1. Ubiquitin plays also an important role in sorting of the EGF receptor from the endosomal system toward the lysosome. This receptor is actively sorted away from the recycling endosome by binding to Hrs, which in turn binds the flat clathrin coat on the endosome (Madshus \& Stang, 2009). Hrs binds to the ESCRT-I component Tsg101 that delivers the EGF receptor to the ESCRT machinery. Incorporation of the EGF receptor into intraluminal vesicles depends on the DUBs AMSH and USP8 that are associated with the ESCRT-III machinery (Row et al., 2007). However, other studies have shown that USP8 can also act, earlier at the level of ESCRT-I, by preventing entry into multivesicular bodies promoting recycling. The interaction of USP8 to both ESCRT-I and ESCRT-III indicates a complex role for this DUB in sorting of endosomal cargo (Berlin et al., 2010). 
For the cytokine receptors interferon- $\alpha$ receptor chain 1 (IFNAR1), the prolactin, the erythropoietin and $\mathrm{GH}$ receptor, $\beta \operatorname{TrCP}$, the substrate recognizing subunit of the E3 ligase complex skip-culling-F-box (SCF), is essential for endocytosis and degradation (Kumar et al., 2004, Li et al., 2004, Meyer et al., 2007, van Kerkhof et al., 2007). Clearly, cytokine receptors appear particularly well regulated by the ubiquitin system. To identify additional regulators of ubiquitylation events involved in trafficking of cytokine receptors we used our model, the GH receptor.

The GH receptor plays an important role in growth and metabolic pathways. In contrast to the EGF receptor, the GH receptor is constitutively endocytosed and degraded in lysosomes. Using a temperature-sensitive E1 mutant, we previously showed that endocytosis is clathrin-mediated and depends on an intact ubiquitin system (Strous et al., 1996). This activity is mediated via the ubiquitin-dependent endocytosis (UbE) motif, a 12 amino acid stretch in the cytosolic tail of the GH receptor (Govers et al., 1999). The ring E3 ligase $\mathrm{SCF}(\beta \operatorname{TrCP})$ binds to the $\mathrm{UbE}$ motif and this binding is required for proper endocytosis (van Kerkhof et al., 2007). Recently, it was shown that, in addition to endocytosis, $\beta \operatorname{TrCP}$ is involved in sorting the GH receptor from multivesicular bodies towards the lysosome (van Kerkhof et al., 2011). In the absence of $\beta \operatorname{TrCP}$, transport of the GH-GH receptor complex is halted at the multivesicular bodies and routed back to the plasma membrane. Interestingly, ubiquitylation of the receptor itself is not required for proper sorting, but it does require binding of this E3 ligase. These findings suggest that the GH receptor travels from the cell surface to the lysosome using $\beta \operatorname{TrCP}$ as a cargo-specific adapter that ubiquitylates (an ancillary factor of) the machinery instead of the cargo itself. In this study we used small interfering ribonucleic acid (siRNA) in a cell-based assay to find additional regulators of ubiquitylation involved in the fate of $\mathrm{GH}$ receptors expressed at the cell surface. We screened a library of siRNAs targeting DUBs and other ubiquitylation factors for their involvement in $\mathrm{GH}$ receptor sorting towards the lysosomes.

\section{Materials and methods}

\subsection{Antibodies, chemicals, and cells}

The DUB siRNA library (Table 1) was obtained from Dharmacon, Thermo Scientific. Anti GH receptor (B) was previously described (van Kerkhof et al., 2000). Anti-actin was obtained from ICN. Lipofectamine2000 was obtained from InVitrogen. Butyrate was obtained from Sigma. NHis6-GH receptor expressing HepG2 cells ware grown in MEM (InVitrogen), supplemented with 10\% FCS, 100 units $/ \mathrm{ml}$ penicillin and $0.1 \mathrm{mg} / \mathrm{ml}$ streptavidin and geneticin. GH receptor U2OS cells were generated and propagated as described in van Kerkhof et al., 2011.

\subsection{SiRNA transfection and screening}

Mixtures of $0.07 \mu \mathrm{l}$ lipofectamine2000 and siRNAs in a total volume of $10 \mu \mathrm{l}$ Optimem with a final concentration of $48 \mathrm{nM}$ siRNA per well (348 well plates) were incubated for $30 \mathrm{~min}$ at 
room temperature. Four thousand Nhis6-GH receptor expressing HepG2 cells were added to the mixture and allowed to propagate. After $48 \mathrm{~h}, 10 \mathrm{mM}$ butyrate was added to increase the expression of $\mathrm{GH}$ receptor. After $72 \mathrm{~h}$, the cells were incubated at $37^{\circ} \mathrm{C}$ with $5 \mathrm{ng} / \mu \mathrm{C} \mathrm{Cy3-}$ $\mathrm{GH}$ for $30 \mathrm{~min}$, and fixed with $3 \%$ paraformaldehyde for $4 \mathrm{~h}$ at room temperature. After three 5-min washes with PBS, cells were incubated with $50 \mu \mathrm{l}$ DAPI, $0.5 \mu \mathrm{g} / \mathrm{ml}$ for $10 \mathrm{~min}$ and washed with PBS. Automated image acquisition was performed by the BD Pathway 855 system (BD Bioscience). DAPI was used for focusing and 4 images per well were acquired using a 20x objective.

\begin{tabular}{|c|c|c|c|c|c|c|c|}
\hline $\begin{array}{c}\text { Gene } \\
\text { Symbol }\end{array}$ & $\begin{array}{c}\text { Accession } \\
\text { Number }\end{array}$ & $\begin{array}{c}\text { Gene } \\
\text { Symbol }\end{array}$ & $\begin{array}{c}\text { Accession } \\
\text { Number }\end{array}$ & $\begin{array}{c}\text { Gene } \\
\text { Symbol }\end{array}$ & $\begin{array}{c}\text { Accession } \\
\text { Number }\end{array}$ & $\begin{array}{c}\text { Gene } \\
\text { Symbol }\end{array}$ & $\begin{array}{c}\text { Accession } \\
\text { Number }\end{array}$ \\
\hline ATXN3L & XM045705 & $\underline{\mathrm{UBE} 1 \mathrm{C}}$ & NM003968 & $\underline{\text { UBL4 }}$ & NM014235 & USP33 & NM015017 \\
\hline BAP1 & NM004656 & $\underline{\text { UBE1DC1 }}$ & NM024818 & $\underline{\text { UBL5 }}$ & NM024292 & USP34 & XM291018 \\
\hline COPS5 & NM006837 & $\underline{\text { UBE1L }}$ & NM003335 & $\underline{\text { UBR1 }}$ & NM174916 & USP35 & XM290527 \\
\hline CXORF53 & NM024332 & $\underline{\mathrm{UBE} 2 \mathrm{~A}}$ & NM003336 & $\underline{\text { UBTD1 }}$ & NM024954 & USP36 & NM025090 \\
\hline CYLD & NM015247 & UBE2B & NM003337 & UCHL1 & NM004181 & USP37 & NM020935 \\
\hline DUB1A & XM377830 & UBE2C & NM007019 & UCHL3 & NM006002 & USP38 & NM032557 \\
\hline DUB3 & NM201402 & $\underline{\text { UBE2D1 }}$ & NM003338 & UCHL5 & NM015984 & USP39 & NM006590 \\
\hline$\underline{\mathrm{FBXO7}}$ & NM012179 & UBE2D2 & NM003339 & UEV3 & NM018314 & USP4 & NM003363 \\
\hline$\underline{\mathrm{FBXO8}}$ & NM012180 & UBE2D3 & NM003340 & UFD1L & NM005659 & USP40 & NM018218 \\
\hline FLJ14981 & NM032868 & UBE2E1 & NM003341 & USP1 & NM003368 & USP41 & XM036729 \\
\hline JOSD1 & NM014876 & UBE2E2 & NM152653 & USP10 & NM005153 & USP42 & XM166526 \\
\hline LOC391622 & NM212553 & $\underline{\mathrm{UBE}} 2 \mathrm{E} 3$ & NM006357 & USP11 & NM004651 & USP43 & XM371015 \\
\hline MJD & NM004993 & UBE2G1 & NM003342 & USP12 & NM182488 & USP44 & NM032147 \\
\hline MYSM1 & XM055481 & $\underline{\mathrm{UBE}} 2 \mathrm{G} 2$ & NM003343 & USP13 & NM003940 & USP45 & XM371838 \\
\hline OTUB1 & NM017670 & $\underline{\mathrm{UBE}}$ & NM003344 & USP14 & NM005151 & USP46 & NM022832 \\
\hline OTUB2 & NM023112 & UBE2I & & USP15 & NM006313 & USP47 & NM017944 \\
\hline OTUD1 & XM166659 & UBE2J1 & NM016021 & USP16 & NM006447 & USP48 & NM033236 \\
\hline OTUD4 & & UBE2I2 & & USP18 & NM017414 & USP5 & NM003481 \\
\hline OTUD5 & NM017602 & $\underline{\text { UBE2L3 }}$ & NM00 & USP19 & XM496642 & USP50 & NM203494 \\
\hline OTUD6B & NM016023 & UBE2L6 & NM004223 & USP2 & NM004205 & USP51 & NM201286 \\
\hline OTUD7 & NM130901 & UBE2M & NM003969 & USP20 & NM006676 & USP52 & NM014871 \\
\hline PARP11 & NM020367 & $\underline{\text { UBE2N }}$ & NM003348 & USP21 & NM012475 & USP53 & XM052597 \\
\hline$\underline{\text { PRPF8 }}$ & NM006445 & $\underline{\text { UBE2NL }}$ & XM372257 & USP22 & XM042698 & USP54 & NM152586 \\
\hline PSMD14 & NM005805 & $\underline{\text { UBE2Q }}$ & NM017582 & USP24 & XM165973 & USP6 & NM004505 \\
\hline SBBI54 & NM138334 & UBE2R2 & NM017811 & USP25 & NM013396 & USP7 & NM003470 \\
\hline SENP2 & NM021627 & UBE2S & NM014501 & USP26 & NM031907 & USP8 & NM005154 \\
\hline$\underline{\text { SHFM3P1 }}$ & AF174606 & UBE2V2 & NM003350 & USP28 & NM020886 & USP9X & NM004652 \\
\hline STAMBP & NM006463 & UBE3A & NM000462 & USP29 & NM020903 & USP9Y & NM004654 \\
\hline STAMBPL1 & NM020799 & UBE3B & NM130466 & USP3 & NM006537 & VCPIP1 & NM025054 \\
\hline TNFAIP3 & NM006290 & $\underline{\mathrm{UBE} 4 \mathrm{~A}}$ & NM004788 & USP30 & NM032663 & YOD1 & NM018566 \\
\hline TRFP & NM004275 & UBE4B & NM006048 & USP31 & NM020718 & ZA20D1 & NM020205 \\
\hline UBE1 & NM003334 & $\underline{\text { UBL3 } 3}$ & NM007106 & USP32 & NM032582 & ZRANB1 & NM017580 \\
\hline
\end{tabular}

Table 1. DUB siRNA library. ${ }^{2}$ Underlined genes are ubiquitin-related proteins without DUB activity 


\subsection{Western blotting}

$\mathrm{GH}$ receptor expressing $\mathrm{U} 2 \mathrm{OS}$ cells were transfected with the siRNAs to silence the indicated genes. Cells were lysed in $1 \%$ Triton X-100, $10 \mu \mathrm{g} / \mathrm{ml}$ leupeptin, $10 \mu \mathrm{g} / \mathrm{ml}$ aprotinin and $1 \mathrm{mM}$ PMSF in PBS for $20 \mathrm{~min}$ and centrifuged at $13,000 \times \mathrm{g}$ for $5 \mathrm{~min}$ at $4^{\circ} \mathrm{C}$. The supernatant was boiled in Laemmli sample buffer, and the proteins were separated on SDSPAGE and transferred to Immobilon-FL polyvinylidenedifluoride membrane (Millipore). Blots were immunostained with primary antibodies followed by Alexa Fluor 680 or IRDye 800 conjugated anti-mouse or anti-rabbit antibodies. An Odyssey system was used for detection (Li-Cor Biosciences, Lincoln NE).

\section{Results}

\subsection{High throughput screening}

$\mathrm{GH}$ receptor transport from the plasma membrane toward the lysosome is a complex process that requires, in addition to general endocytosis factors, specific regulatory proteins. As the ubiquitin system was implied in this process (Govers et al., 1997), we set up an assay to identify novel modifiers of regulatory ubiquitilation involved in GH uptake.

Since the liver is an important target of $\mathrm{GH}$, we used the human hepatocellular carcinoma cell line HepG2 for this assay. These epithelial cells are non-tumorigenic and synthesize a variety of liver-specific proteins, such as the asialoglycoprotein receptor and several plasma proteins (albumin, transferrin and the acute phase proteins fibrinogen, $\beta 2$-macroglobulin, $\alpha 1$-antitrypsin, and plasminogen). Although HepG2 cells are GH sensitive, they have insufficient GH receptors to probe the effect of gene silencing. Therefore, we constructed a HepG2 cell line that expresses 100-200,000 rabbit GH receptors per cell. To identify genes involved in GH receptor endocytosis and degradation, we transfected the $\mathrm{GH}$ receptor expressing HepG2 cells with siRNAs as indicated. After $72 \mathrm{~h}$, the cells were allowed to take up $\mathrm{GH}$ conjugated with $\mathrm{Cy} 3(\mathrm{Cy} 3-\mathrm{GH})$ for $30 \mathrm{~min}$ at $37^{\circ} \mathrm{C}$, after which they were immediately fixed and assessed for Cy3-GH uptake (Fig. 1).

We screened a commercial siRNA library targeting 84 DUBs and 44 other ubiquitylationrelated enzymes (Table 1) for regulators of GH uptake and receptor sorting (Dharmacon). This arrayed library consists of siRNA pools constituted of 4 unique siRNA sequences, targeting a specific gene (Dharmacon). The screen was performed in a 384 well plate format and an automated spinning-disc confocal microscope was used for unbiased image acquisition, 4 images per well, of Cy3-GH and DAPI signal. The experiment itself was performed in duplicate yielding eight data points per gene. Hits were called when at least 3 out of 4 wells showed a similar phenotype. The assessment of hits was done manually in a double blind fashion by two researchers, independently. The hits were ordered in three categories: Category I, Cy3-GH enrichment on the plasma membrane, category II, Cy3-GH enrichment on both the plasma membrane and intracellular, and category III, intracellular enrichment only. Clathrin heavy chain and Tsg101 depletion, involved in clathrin-mediated endocytosis and in sorting at multivesicular bodies, respectively, were used as controls. Fig. 
1 (first row) shows that clathrin depletion resulted in accumulation of $\mathrm{Cy} 3-\mathrm{GH}$ at the plasma membrane, whereas Tsg101 depletion resulted in Cy3-GH accumulation in both internal vesicles and on the plasma membrane. These data show that our screen setup has sufficient sensitivity to detect accumulation of GH receptor. Using the same method we identified 13 genes: 7 in category I, 3 in category II and 3 in category III (Table 2). The E1 enzyme (UBE1) was identified as a category I hit, in concordance with its previously described role in GH receptor endocytosis (Strous et al., 1997)

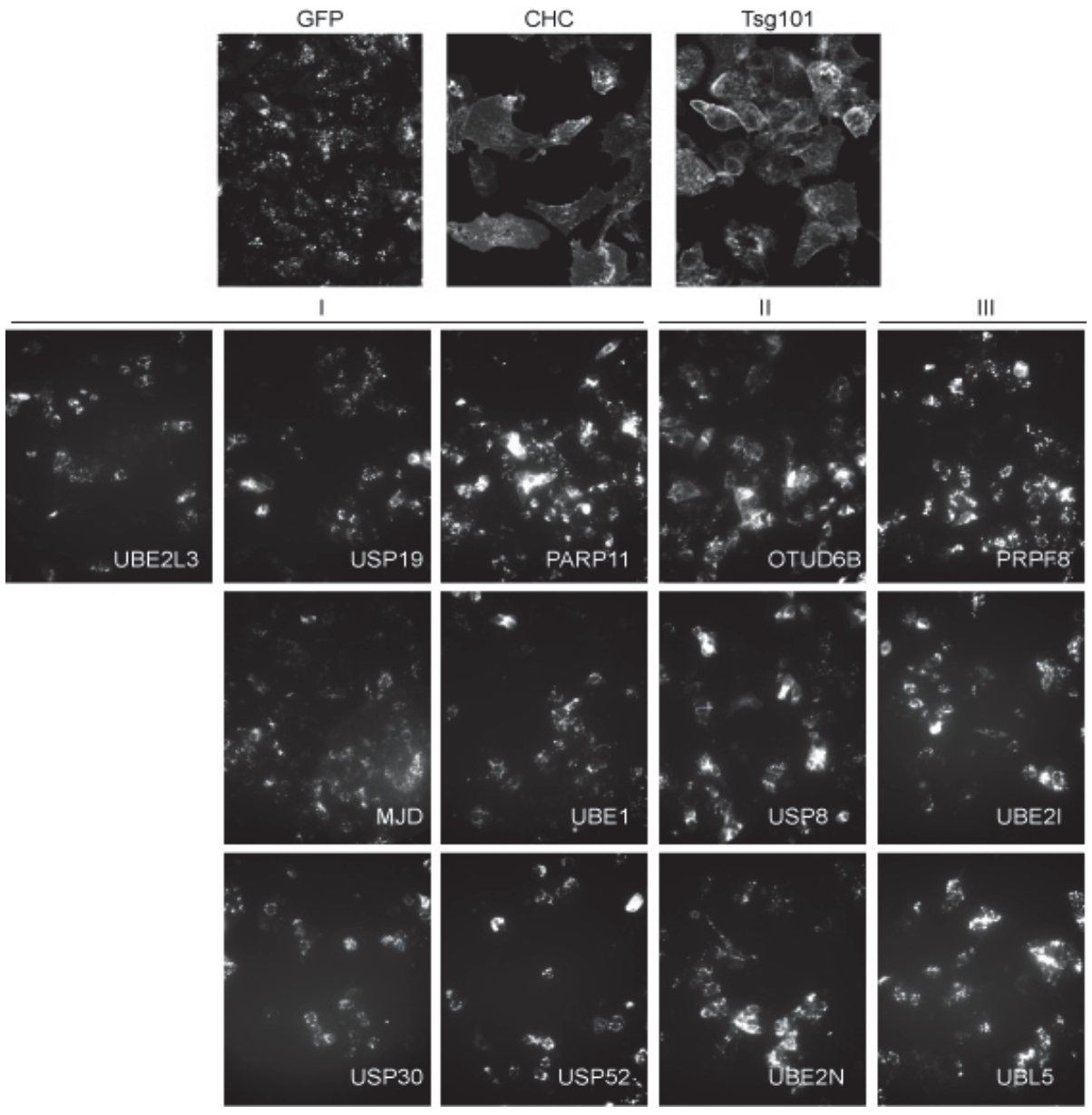

Figure 1. Representative images of observed phenotypes in the screen. Cells were transfected with smartpool siRNA, containing 4 individual siRNAs directed against a specific target. After $72 \mathrm{~h}$, cells were incubated with $\mathrm{Cy} 3-\mathrm{GH}$ at $37^{\circ} \mathrm{C}$ for $30 \mathrm{~min}$ and fixed. Four images of the samples were automatically acquired, and analysed by eye. All the targets that were considered hits are shown. The image is a representative of 2 experiments. The images are grouped according to three pheno-typical categories: I: Cy3-GH enrichment on the plasma membrane, II: Cy3-GH enrichment on both the plasma membrane and intracellular, and III: intracellular enrichment only. 


\begin{tabular}{|c|c|c|c|}
\hline Gene & Protein & Function & Cat \\
\hline USP19 & $\begin{array}{l}\text { Ubiquitin carboxyl-terminal } \\
\text { hydrolase } 19\end{array}$ & DUB functioning in ER folding & $\mathbf{I}$ \\
\hline MJD & Ataxin-3 & $\begin{array}{l}\text { DUB functions in IGF-1 signalling and } \\
\text { longevity in C. Elegans }\end{array}$ & $\mathbf{I}$ \\
\hline USP30 & Ubiquitin specific protease 30 & $\begin{array}{l}\text { DUB located at outer mitochondrial } \\
\text { membrane, function unknown }\end{array}$ & $\mathbf{I}$ \\
\hline OTUD6B & OTU domain containing 6B & $\begin{array}{l}\text { Member of the otubain DUB family, } \\
\text { function unknown }\end{array}$ & II \\
\hline PARP11 & $\begin{array}{l}\text { poly (ADP-ribose) polymerase } \\
\text { family, member } 11\end{array}$ & $\begin{array}{l}\text { Poly (ADP-ribose) polymerase family } \\
\text { member, mRNA processing }\end{array}$ & I \\
\hline PRPF8 & $\begin{array}{l}\text { pre-mRNA processing factor } 8 \\
\text { (PRPF8 homolog, yeast) }\end{array}$ & $\begin{array}{l}\text { mRNA processing factor functions in } \\
\text { the spliceosome }\end{array}$ & III \\
\hline UBE1 & $\begin{array}{l}\text { Ubiquitin activating enzyme } \\
\text { E1 }\end{array}$ & Human ubiquitin-activating enzyme E1 & I \\
\hline USP52 & Ubiquitin specific peptidase 52 & DUB, function unknown & I \\
\hline USP8 & ubiquitin specific peptidase 8 & $\begin{array}{l}\text { DUB, involved in EGF receptor sorting } \\
\text { at multivesicular bodies }\end{array}$ & II \\
\hline UBE2I & $\begin{array}{l}\text { ubiquitin-conjugating enzyme } \\
\text { E2I (UBC9 homolog, yeast) }\end{array}$ & $\begin{array}{l}\text { Human homolog of UBC9, activating } \\
\text { enzyme for ubiquitin like protein } \\
\text { SUMO }\end{array}$ & III \\
\hline UBE2L3 & $\begin{array}{l}\text { ubiquitin-conjugating enzyme } \\
\text { E2L } 3\end{array}$ & $\begin{array}{l}\text { Ubiquitin conjugating enzyme, cell } \\
\text { cycle, can function together with Triad1 }\end{array}$ & I \\
\hline UBE2N & $\begin{array}{l}\text { ubiquitin-conjugating enzyme } \\
\text { E2N (UBC13 homolog, yeast) }\end{array}$ & $\begin{array}{l}\text { Ubiquitin conjugating enzyme able to } \\
\text { catalyse K-63 linked ubiquitin chains }\end{array}$ & II \\
\hline UBL5 & $\begin{array}{c}\text { ubiquitin-like protein } 5 \\
\text { (BEACON homolog, human) }\end{array}$ & $\begin{array}{l}\text { Ubiquitin like protein, differentially } \\
\text { expressed between lean and obese }\end{array}$ & III \\
\hline
\end{tabular}

Table 2. Screening results: Genes with a phenotype

\subsection{Validation of hits}

To validate candidate genes, we tested 8 siRNA pools with the strongest phenotypes in the first screen (USP19, Ubc9, Usp52, Usp8, Ubc13, Ubl5, PRPF8, and OTUD6B) in a second screen using a different cell type. For this purpose, we transfected osteosarcoma U2OS cells with rabbit GH receptor and selected a clone that expressed a limited number of exogenous GH receptors (Fig. 2A). In our experience, U2OS cells have a limited capacity to endocytose cargo via the clathrin-mediated pathway, a feature that renders the endocytosis assay particularly sensitive. In addition to the siRNA pools we transfected the individual siRNAs that constituted the pools (data not shown). In all cases at least 2 out of 4 siRNAs showed a similar phenotype as the pool, decreasing the likelihood of off-target effects. These 8 hits were examined in more detail. 


\subsubsection{Usp19}

Usp19 depletion showed an overall increase in Cy3-GH signal as well as some cell surface labelling (Fig 2A). Usp19 is an ER-localized membrane protein (Hassink et al., 2009), which was originally identified as a DUB induced in atrophying muscle (Combaret et al., 2005). It stabilizes ER localized proteins like CFTR and TCR $\alpha$ (Hassink et al., 2009) as well as cytosolic proteins like Hif1 $\alpha$, Siah1 and 2, c-IAP1 and 2, and the cyclin-dependent kinase inhibitor regulating ubiquitin ligases KPC1 and 2 (Altun et al., 2012, Lu et al., 2009, Mei et al., 2011). Interestingly, the catalytic activity of USP19 does not seem to be required for the stabilization of its substrates, but for stabilization of itself, facilitated via self-association (Altun et al., Mei et al., 2011). It also modulates transcription of major myofibrillar proteins (Sundaram et al., 2009), probably in a similar way as the earlier mentioned proteins. Furthermore, Usp19 is upregulated in smoke-induced muscle atrophy conditions in mice (Liu et al., 2011).
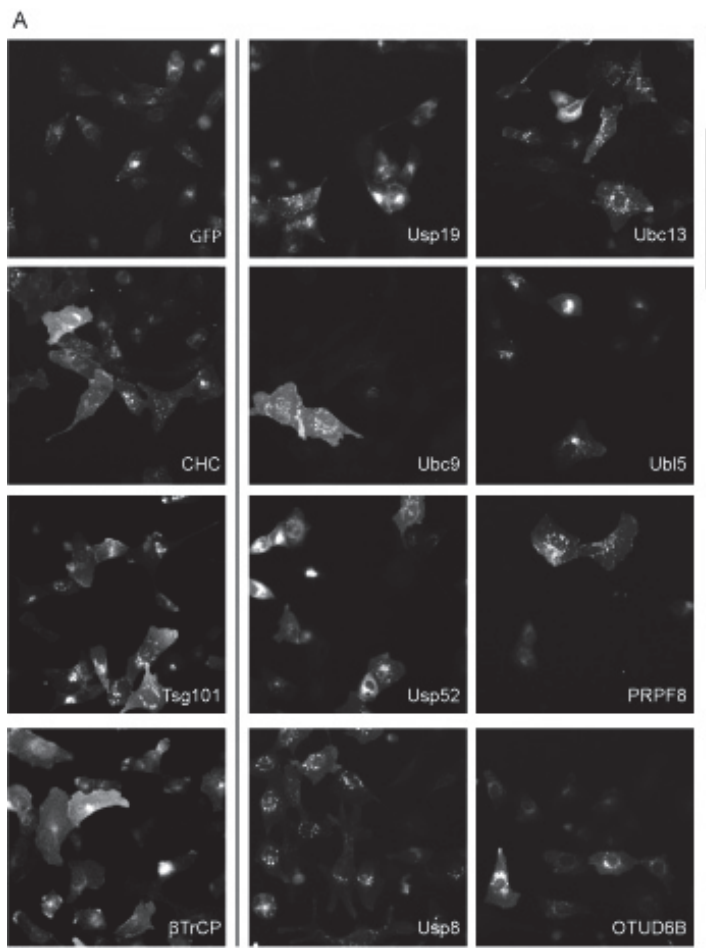

B
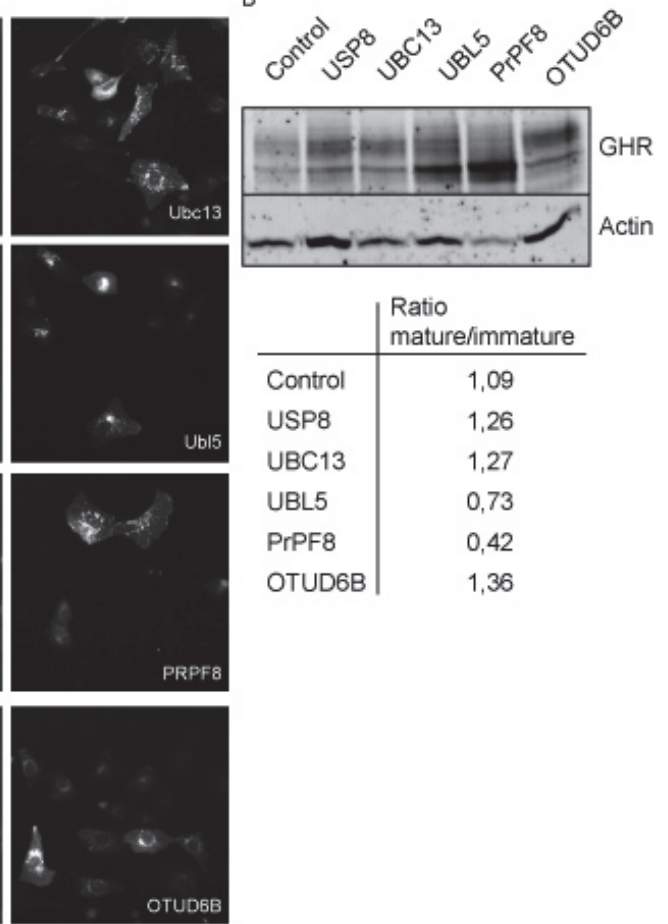

Figure 2. Validation of hits obtained by the initial screen. GH receptor expressing U2OS cells were transfected with siRNAs as indicated. A) After $72 \mathrm{~h}$, the cells were allowed to take up Cy3-GH for 30 min at $37^{\circ} \mathrm{C}$ and immediately fixed. Cy3-GH uptake was assessed by automated confocal microscopy; images are representative of 4 experiments. B) After $72 \mathrm{~h}$, cells were lysed and proteins were separated by SDS-PAGE followed by Western blot analysis for GH receptor (GHR) using actin as a loading control. The upper GHR band represents the mature GHR, while the lower band is the immature (ER) form. The ratio mature/immature for the GHR species was taken as a measure for the turnover of the GHR related to the steady state situation in control cells. 
Since the predominant splice variant is a type IV membrane protein, USP19 might act as an ER resident protein with no direct role in GH receptor regulation at the endosomal level. Further characterization was beyond the scope of this study. Alternative roles in the cytosol will undoubtedly become clear in the future.

\subsubsection{Usp8}

Usp8, also known as UBPY, is a deubiquitylating enzyme that functions in protein sorting at multivesicular bodies. Depletion of Usp8 showed a perinuclear accumulation of Cy3-GH punctae (Fig. 2A), reminiscent of the phenotype resulting from Tsg101 depletion. To characterize the effects of gene silencing on the GH receptor degradation further we performed Western blot analysis for the GH receptor. This approach reveals additional details related to the role of USP8 in GH receptor trafficking. At steady state, Western blot analyses of the GH receptor show an approximately 1:1 ratio of the amount of 'immature' (high mannose oligosaccharides-containing) receptor, mainly located in the rough ER, and the amount of the 'mature', complex-glycosylated GH receptor, mainly present at the plasma membrane. Previously, we determined the half-life of both GH receptor species to be $50 \mathrm{~min}$ at $37^{\circ} \mathrm{C}$. The half-life of the high-mannose $\mathrm{GH}$ receptor is defined as the time it takes for the GH receptor to exit the ER and arrive at the Golgi complex to receive the 'complex' sugar moieties, while the half-life of the 'mature' GH receptor is defined as the time required for its transport from plasma membrane to the lysosomes. As Usp8 depletion caused a relative increase in mature over immature GH receptor levels, the results suggest that Usp8 promotes $\mathrm{GH}$ receptor degradation.

Usp8 can bind to ESCRT-III components and its depletion leads to enlarged endosomes and diminished incorporation of EGF receptors into the intraluminal vesicles (ILV) of the multivesicular bodies (Bowers et al., 2006). In addition, it has been reported that Usp8 can interact with the ESCRT-0 component STAM via its SH3 domain and that its depletion results in accelerated degradation of EGF receptor in the lysosome, strongly suggesting that Usp8-dependent deubiquitylation of EGF receptor prevents EGF receptor from being recognized by the ESCRT machinery, a recognition depending on ESCRT-0 component Hrs (Berlin et al., 2010, Rao et al., 2011). Furthermore, the ability of Usp8 to bind both ESCRT-I and ESCRT-III suggests a dual function for Usp8 in receptor sorting. Indeed, at the plasma membrane Usp8 can inhibit degradation of receptors by removing the ubiquitin tag that directs them to the multivesicular bodies, while at the multivesicular bodies Usp8 can promote degradation of receptors by allowing incorporation of receptors into the ILVs (Wright et al., 2011). We demonstrate here that depletion of Usp8 increases the level of intracellular GH receptor indicative of a defect in sorting towards the lysosome, most likely at the level of ESCRT-III. The latter is supported by previous data showing that the transport of $\mathrm{GH}$ receptor from multivesicular bodies to the lysosome does not depend on ESCRT-0 components. Apparently, the GH receptor enters the ESCRT complexes at the level of ESCRT-I (van Kerkhof et al., 2011). 


\subsubsection{Ubl5}

Ubl5 depletion leads to an increased accumulation of Cy3-GH in endosomes. The Western blot analyses showed a complex pattern wherein both the immature $\mathrm{GH}$ receptor band and the mature GH receptor were increased compared to control cells. Ubl5 is a small ubiquitin like modifier that, in contrast to other ubiquitin like molecules, does not have a C-terminal glycine residue. A remarkable finding implicated a mutation in non-coding regions of Ubl5 in metabolic syndrome-related phenotypes (Bozaoglu et al., 2006). In a recent study, Mishra and co-workers show that its yeast homologue Hub1 alters the splice specificity for certain non-canonical 5' splice sites by non-covalent attachment to elements of the spliceosomes (Mishra et al., 2011). Combining the above renders it plausible that expression levels of Ubl5, altered by mutations in the non-coding region, attenuate the expression of proteins ultimately affecting metabolism. Since the GH receptor is tightly involved in regulation of metabolic pathways, the involvement of Ubl5 in GH receptor trafficking toward the lysosome is interesting. Either the $\mathrm{GH}$ receptor itself or $\mathrm{GH}$ receptor-regulating factors might be affected by Ubl5. Preliminary data from ${ }^{125} \mathrm{I}-\mathrm{GH}$ uptake experiments suggest that depletion of Ubl5 does not alter the internalization and degradation kinetics of the receptor. Furthermore, a direct interaction between the GH receptor and Ubl5 could not be identified (data not shown). Since steady state levels of GH receptor as measured with Western blot analyses did increase as a result of Ubl5 silencing (Fig. 2B), the data suggest that Ubl5 either influences transcription or synthesis of the GH receptor. To fully understand the role of Ubl5 more investigation is required.

\subsection{4. $\operatorname{PrPF8}$}

Pre-mRNA-processing-splicing factor 8 (PrPF8) is a large nuclear protein that functions in the U2, U12 and trans-spliceosome, and has an active role in processing of pre-mRNA (reviewed in Grainger \& Beggs, 2005). PrPF8 knockdown showed an intracellular accumulation of Cy3-GH. In addition, the Western blot analysis showed an increase in the immature form of $\mathrm{GH}$ receptor and a complex band pattern of slower migrating bands. This might indicate that multiple pathways are affected. Because of PrpF8's role in the spliceosome, it is likely that depletion of this protein can influence correct splicing of many factors including the GH receptor and proteins of the endocytosis machinery. We did not yet elucidate whether PrPF8 is directly or indirectly involved in GH receptor endocytosis. For example, previously, we have shown that alternative splicing of $\beta \operatorname{TrCP}$ isoforms may affect their localization, which may have consequences for $\mathrm{GH}$ receptor endocytosis (Putters et al., 2011b). Because the GH receptor mRNA was artificially transcribed from a plasmid driven by a CMV promoter (pcDNA3) it is possible that this might indirectly lead to alterations in sorting of $\mathrm{GH}$ receptor at the plasma membrane or at endosomes by exceeding the sorting capacity of these systems. Alternatively, absence of PrPF8 may affect the balance of folding factors in the ER, resulting in ER overload of GH receptors that cannot leave the ER, e.g. due to defective dimerization (van den Eijnden et al., 2006). 


\subsubsection{OTUD6B}

Ovarian tumour (OTU) domain containing 6B (OTUD6B) is a member of the OTU-domain Ubal-binding protein (otubain) domain containing protein family that constitutes a specific subset of deubiquitylating enzymes. The function of OTUD6B is not known. Substrates of two other OTU domain containing proteins, OTUB1 and OTUB2, are GRAIL (Soares et al., 2004), oestrogen receptor (Stanisic et al., 2009), p97 (Ernst et al., 2009), RhoA (Edelmann et al.), Traf3 and Traf6 (Li et al., 2010). They have been implicated in non-canonical DNAdamage response (Nakada et al., 2010). Furthermore, OTUB1 shows substrate specificity towards K48 linked ubiquitin chains (Wang et al., 2009). We have identified OTUD6B as a novel factor in $\mathrm{GH}$ receptor endocytosis. Its depletion leads to a phenotype where mature $\mathrm{GH}$ receptor accumulates, mainly in the endosomes but also at the plasma membrane. Fig. 2B clearly shows a decreased degradation with little effect on its biosynthesis. Analogous to Tsg101 depletion, this might point to a role in multivesicular body function. Further investigations are necessary to determine whether OTUB6D acts specific on the GH receptor or has a general role in endosomal sorting.

\subsubsection{Ubc13 and associated E3s}

The presence of UBE2N, encoding for the E2 enzyme Ubc13, in our hit list was striking. Previously, after our finding that ubiquitylation is required for $\mathrm{GH}$ receptor endocytosis and degradation, we identified $\mathrm{SCF}(\beta \mathrm{TrCP})$ as an E3 that specifically binds to the UbE motif of the GH receptor and conjugates K48 poly-ubiquitin chains to the GH receptor (Putters et al., 2011a, van Kerkhof et al., 2007). With the identification of Ubc13 it became plausible that also K63-linked ubiquitin chains might be involved in GH receptor endocytosis, as Ubc13 together with the pseudo E2s UEV1A and MMS2 can synthesize K63 linked ubiquitin chains (Deng et al., 2000).

\begin{tabular}{|c|c|c|c|}
\hline Gene & Protein & Function & Reference \\
\hline ARIH2* & Triad1 & Cell cycle, cell growth & (Marteijn et al., 2009) \\
\hline $\mathrm{CHFR}^{*}$ & CHFR & Cell cycle & (Bothos et al., 2003, Loring et al., 2008) \\
\hline PARK2* & Parkin & $\begin{array}{c}\text { Neuroprotection, cell } \\
\text { death }\end{array}$ & (Lo Bianco et al., 2004) \\
\hline $\mathrm{RNF}^{*}$ & RNF8 & DNA repair & (Plans et al., 2006) \\
\hline Rad5 & Rad5 & DNA repair & (Torres-Ramos et al., 2002) \\
\hline Rad18 & PCNA & DNA repair & (Ulrich \& Jentsch, 2000) \\
\hline STUB1* & CHIP & Heat shock system & (Zhang et al., 2005) \\
\hline TRAF2 & Traf2 & TNF signalling & (Habelhah et al., 2004) \\
\hline TRAF6 & Traf6 & TNF signalling & (Wooff et al., 2004) \\
\hline
\end{tabular}

Table 3. E3 ligases known to interact with Ubc13 
Furthermore, these K63-linked ubiquitin chains have been implied in endocytosis in yeast (Lauwers et al., 2009) and in mammalian cells (Kamsteeg et al., 2006). To investigate whether K63-linked ubiquitylation is indeed involved in GH receptor endocytosis, we selected nine E3 ubiquitin ligases that are known to interact with Ubc13 (listed in Table 3) (Bothos et al., 2003, Deng et al., 2000, Loring et al., 2008, Marteijn et al., 2009, Plans et al., 2006, Sun et al., 2004, Torres-Ramos et al., 2002, Zhang et al., 2005). As gene silencing of Traf2 and Traf6 induced cell death in previous experiments (data not shown), and rad5 and rad18 are mainly involved in DNA repair, we excluded them from further investigation and performed gene silencing experiments for the 5 remaining E3 ligases using validated siRNAs (Table 3, asterisk).

We transfected GH receptor-expressing U2OS cells with these siRNAs and propagated them for 3 days prior to performing the assay as described above. Cells, treated with siRNAs for ARIH2 and STUB1, encoding Triad1 and CHIP, respectively, showed a strong phenotype (Fig. 3). Not only was the label intensity much higher, silencing of both genes also induced accumulation of Cy3-GH signal on the plasma membrane. Recently, we published details about the role of the ubiquitin ligase CHIP in GH receptor endocytosis involving a direct interaction with specific amino acid sequences in the cytosolic tail of the receptor. The same study shows that CHIP acts in collaboration with UBC13, implicating K63-specific ubiquitylation in the GH receptor endocytosis (Slotman et al., 2012). This is in accordance with Fig. 2.
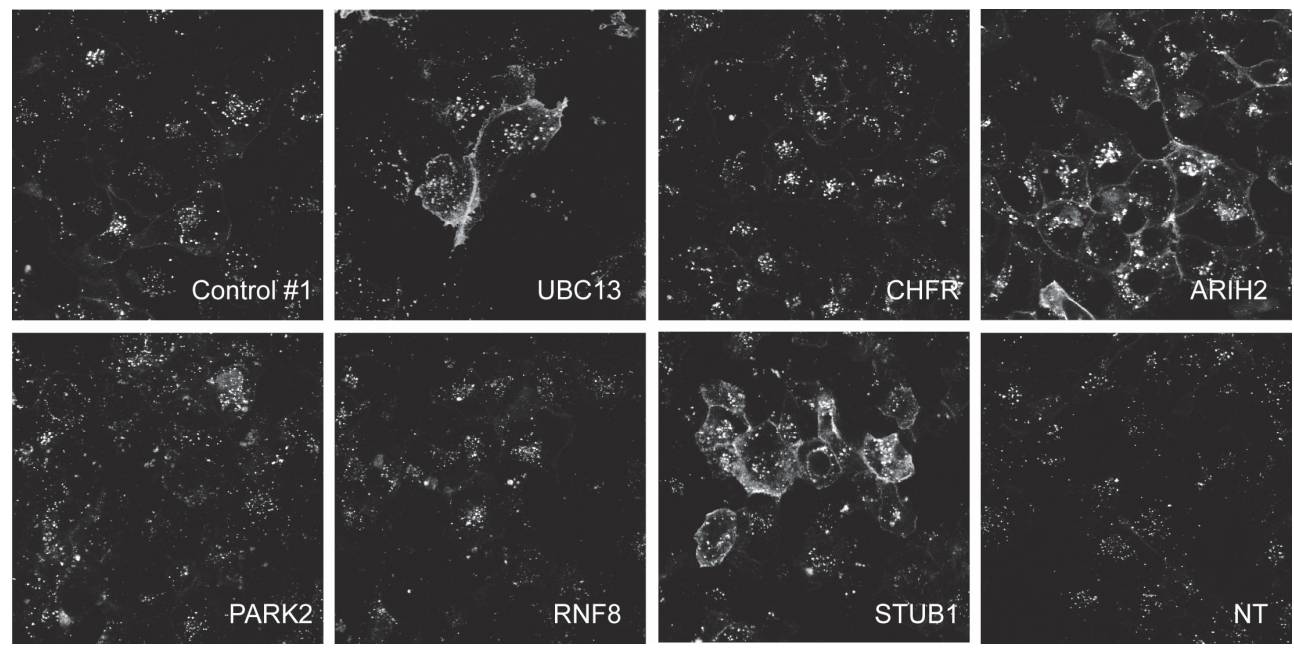

Figure 3. Mini-screen for E3s involved in Ubc13 mediated ubiquitylation. GH receptor-expressing U2OS cells were transfected with validated siRNAs targeting $5 \mathrm{E} 3$ ligases that can function together with the E2 Ubc13. After $72 \mathrm{~h}$, the cells were allowed to take up $\mathrm{Cy} 3-\mathrm{GH}$ at $37^{\circ} \mathrm{C}$ for $30 \mathrm{~min}$ after which they were fixed. Cy3-GH uptake was assessed by confocal microscopy. Shown cells are representative for all cells in the samples of 2 independent experiments. 
Triad1-depleted cells showed larger internal vesicles with an altered pattern as compared to wild type. Triad1 is an E3 ligase that has 2 RING domains and, consequently, has the ability to bind two ubiquitin conjugases. Previously, Marteijn and co-workers identified both Ubc13 and UbcH7 as E2s involved in Triad1 action (Marteijn et al., 2009). As seen in Fig. 1 and Table 2, UBCH7 (UBE2L3) also tested positive in our initial screen, strengthening the involvement of Triad1 in the sorting of GH receptors in endosomes (Fig. 1, Table 2)

In conclusion, we identified three novel genes in GH-induced endocytosis via the GH receptor, two of which (UBC13 and STUB1) demonstrated identical phenotypes, while silencing of ARIH2 resulted in a different pattern. All three enzymes are involved in K63linked ubiquitin chain formation. Further studies are being performed to determine whether ARIH2 acts specifically on the GH receptor or whether it has a broader function in endocytosis and/or lysosomal degradation (Hassink et al., 2012).

\section{Discussion}

We performed a siRNA screen in which we assayed 84 DUBs and 44 other enzymes of the ubiquitin and related systems. In the first screen we identified 13 genes that showed an altered uptake or degradation pattern of Cy3-GH. As expected, the UBE1 gene, encoding the E1 enzyme, one of two ubiquitin activating enzymes in mammalian cells, was among the 13 hits. It is known that by disrupting the enzymatic activity of the E1 enzyme GH receptor endocytosis is blocked (Strous et al., 1996). The observation that E1 silencing results in a similar phenotype shows that the screen setup is valid and able to pick up factors of the ubiquitin system that are involved in (GH receptor) endocytosis. Furthermore, the large number of hits in this screen clearly shows that $\mathrm{GH}$ receptor trafficking by ubiquitin is a complex and well regulated process.

Among the proteins that did not appear in our screen as a hit, but would be expected to show a phenotype, is the activating enzyme (E1) of the ubiquitin like modifier ISG15. ISG15ylation of Ubc13 disrupts its function (Zou et al., 2005) and depletion of this E1 would lead to less ISG15ylation of Ubc13 that might result in an increased endocytosis of GH receptor. Unfortunately, our approach lacks the sensitivity to register accelerated endocytosis. An assay that would pick up such an effect must be suited to measure endocytosis in a quantitative way rather than qualitatively. Another factor that we expected to find was UBE2M, which functions as the E2 for neddylation of cullins, the modification by the ubiquitin like protein Nedd8. Cullin neddylation activates $\operatorname{SCF}(\beta \operatorname{TrCP})$, which is essential for GH receptor ubiquitylation and degradation (van Kerkhof et al., 2007). Recently, the ubiquitin conjugase UBE2F was identified as a Nedd8 conjugating enzyme (Huang et al., 2009). Therefore, UBE2M and UBE2F might have a redundant function, possibly explaining the absence of UBE2M among our hits. Of note, UBE2F was not targeted by our siRNA library and was therefore not tested in our assay. 
The screen identified two proteins involved in ubiquitin-like mechanisms, UBE2I, also known as UBC9, the E2 for SUMOylation, and UBL5, an ubiquitin like protein. This is the first time that these two pathways are implicated in GH receptor trafficking. Many similarities exist between the ubiquitin-based and ubiquitin-like mechanisms with many examples of interplay. In GH receptor trafficking SUMOylation might block ubiquitylation and vice versa (Denuc \& Marfany, 2010). The action of UBL5 is more mysterious, since it cannot be conjugated to substrates due to a lack of a C-terminal glycine residue. Hypothetically, ubiquitin binding domains could be blocked by the structurally very similar UBL5 and in this a way UBL5 may regulate ubiquitylation events (McNally et al., 2003). A correlation between obesity and UBL5 mRNA levels was found in P. obesus (Walder et al., 2002) but this finding is still debated in humans (Bozaoglu et al., 2006, McNally et al., 2003). Since GH receptor signalling is highly involved in growth and obesity (Erman et al., 2010, Gao et al., 2010), altering the sorting of GH receptor could be involved. Hence, GH receptor sorting defects, UBL5, and growth and metabolic diseases may be linked.

We identified two novel ubiquitin ligases that are involved in GH receptor trafficking, $\mathrm{CHIP}$ and Triad1; thus, together with $\mathrm{SCF}(\beta \operatorname{TrCP})$, at least three E3s have a regulatory role in $\mathrm{GH}$ receptor degradation. This indicates that both K48 and K63-linked ubiquitin chain formation are involved. In addition, we identified six DUBs involved in GH receptor endocytosis and homeostasis: USP19, MJD, USP30, OTUD6B, UPS52 and USP8. These DUBs might antagonize the action of the ligases mentioned above, providing a high level regulation. Together, these proteins are part of a complex system that regulates ubiquitylation of many substrates. In part by spatial en temporal regulation, ubiquitylation and deubiquitylation events modulate the sorting of GH receptor, and thereby respond quickly to different forms of stress. Additionally, the number of distinct E2, E3, and DUB enzymes involved in ubiquitylation provides specificity in regulating different classes of receptors in disparate ways within the same endocytic system.

These findings underscore the complexity of the ubiquitylation system and endocytosis process, and, at the same time, offer interesting opportunities to discover drugs that specifically target the GH receptor. As this receptor is implicated both in anabolism, in longevity and insulin sensitivity (Bartke, 2012), drugs that can either up- or down regulate its activity are highly relevant.

\section{Conclusion}

The ubiquitin proteasome system plays an essential role in trafficking of the growth hormone receptor from the plasma membrane to the lysosomes, where degradation takes place. When ubiquitylation is disabled, the GH receptor accumulates at the plasma membrane and its degradation is inhibited. As endosomal sorting is a highly regulated process that depends on a variety of ubiquitylation events, we set up a cell-based, high content siRNA screen targeting 128 genes of the ubiquitylation system. In this study we report the identification of 13 modifiers of regulatory ubiquitylation events that are involved in trafficking and degradation of the GH receptor. As the GH receptor is a key regulator of 
metabolism, this study highlights the complexity of pathways that underlie its regulation. These findings may guide the development of specific drugs that either up- or downregulate GH-based signal transduction. As GH signalling is implicated in longevity, insulinsensitivity, and cancer, studies focussed at factors that regulate ubiquitylation and $\mathrm{GH}$ receptor levels are highly relevant.

\section{Author details}

Johan A. Slotman, Peter van Kerkhof, Gerco Hassink and Ger J. Strous

Department of Cell Biology, University Medical Center Utrecht and

Institute of Biomembranes, Utrecht, The Netherlands

Hendrik J. Kuiken

Netherlands Cancer Institute, Division of Molecular Carcinogenesis, Amsterdam, The Netherlands

\section{Acknowledgement}

This research was supported by the European Network of Excellence, Rubicon "Role of ubiquitin and ubiquitin-like modifiers in cellular regulation" (Grant LSHG-CT-2005-018683), the Marie Curie network, "UbiRegulators", (Grant MRTN-CT-2006-034555), and the Netherlands Proteomics Centre, "Proteomic analysis of ubiquitylation in membrane trafficking, NPC3.1 to JAS. We thank all other members of the GH receptor group for suggestions and helpful discussions.

\section{References}

Altun M, Zhao B, Velasco K, Liu H, Hassink G, Paschke J, Pereira T \& Lindsten K (2012). Ubiquitin-specific protease 19 (USP19) regulates hypoxia-inducible factor 1alpha (HIF1alpha) during hypoxia. J Biol Chem, 287:1962-1969.

Bartke A (2012). Pleiotropic effects of growth hormone signaling in aging. Trends Endocrinol Metab, 22:437-442.

Berlin I, Schwartz H \& Nash PD (2010). Regulation of epidermal growth factor receptor ubiquitination and trafficking by the USP8.STAM complex. J Biol Chem, 285:3490934921.

Bomberger JM, Barnaby RL \& Stanton BA (2010). The deubiquitinating enzyme USP10 regulates the endocytic recycling of CFTR in airway epithelial cells. Channels (Austin), 4:150-154.

Bothos J, Summers MK, Venere M, Scolnick DM \& Halazonetis TD (2003). The Chfr mitotic checkpoint protein functions with Ubc13-Mms2 to form Lys63-linked polyubiquitin chains. Oncogene, 22:7101-7107.

Boulkroun S, Ruffieux-Daidie D, Vitagliano JJ, Poirot O, Charles RP, Lagnaz D, Firsov D, Kellenberger S \& Staub O (2008). Vasopressin-inducible ubiquitin-specific protease 10 increases $\mathrm{ENaC}$ cell surface expression by deubiquitylating and stabilizing sorting nexin 3. Am J Physiol Renal Physiol, 295:F889-900. 
Bowers K, Piper SC, Edeling MA, Gray SR, Owen DJ, Lehner PJ \& Luzio JP (2006). Degradation of Endocytosed Epidermal Growth Factor and Virally Ubiquitinated Major Histocompatibility Complex Class I Is Independent of Mammalian ESCRTII. J Biol Chem, 281:5094-5105.

Bozaoglu K, Curran JE, Elliott KS, Walder KR, Dyer TD, Rainwater DL, VandeBerg JL, Comuzzie AG, Collier GR, Zimmet P, MacCluer JW, Jowett JB \& Blangero J (2006). Association of genetic variation within UBL5 with phenotypes of metabolic syndrome. Hum Biol, 78:147-159.

Butterworth MB \& Johnson JP (2008). USP10: the nexus between nexin and vasopressin. Am J Physiol Renal Physiol, 295:F888.

Combaret L, Adegoke OA, Bedard N, Baracos V, Attaix D \& Wing SS (2005). USP19 is a ubiquitin-specific protease regulated in rat skeletal muscle during catabolic states. Am J Physiol Endocrinol Metab, 288:E693-700.

Deng L, Wang C, Spencer E, Yang L, Braun A, You J, Slaughter C, Pickart C \& Chen ZJ (2000). Activation of the IkappaB kinase complex by TRAF6 requires a dimeric ubiquitin-conjugating enzyme complex and a unique polyubiquitin chain. Cell, 103:351361.

Denuc A \& Marfany G (2010). SUMO and ubiquitin paths converge. Biochem Soc Trans, 38:34-39.

Edelmann MJ, Kramer HB, Altun M \& Kessler BM (2010). Post-translational modification of the deubiquitinating enzyme otubain 1 modulates active RhoA levels and susceptibility to Yersinia invasion. Febs J, 277:2515-2530.

Erman A, Veilleux A, Tchernof A \& Goodyer CG (2010). Human growth hormone receptor (GHR) expression in obesity: I. GHR mRNA expression in omental and subcutaneous adipose tissues of obese women. Int J Obes (Lond), 35:1511-1519.

Ernst R, Mueller B, Ploegh HL \& Schlieker C (2009). The otubain YOD1 is a deubiquitinating enzyme that associates with p97 to facilitate protein dislocation from the ER. Mol Cell, 36:28-38.

Gao L, Zheng Z, Cao L, Shen S, Yang Y, Zhao Z, Zhi D, Cheng R, Pei Z, Yongfu Y \& Luo F (2010). The growth hormone receptor (GHR) exon 3 polymorphism and its correlation with metabolic profiles in obese Chinese children. Pediatr Diabetes, 12:429-434.

Goto E, Yamanaka Y, Ishikawa A, Aoki-Kawasumi M, Mito-Yoshida M, Ohmura-Hoshino M, Matsuki Y, Kajikawa M, Hirano H \& Ishido S (2010). Contribution of lysine 11linked ubiquitination to MIR2-mediated major histocompatibility complex class I internalization. J Biol Chem, 285:35311-35319.

Govers R, ten Broeke T, van Kerkhof P, Schwartz AL \& Strous GJ (1999). Identification of a novel ubiquitin conjugation motif, required for ligand-induced internalization of the growth hormone receptor. Embo J, 18:28-36.

Govers R, van Kerkhof P, Schwartz AL \& Strous GJ (1997). Linkage of the ubiquitinconjugating system and the endocytic pathway in ligand-induced internalization of the growth hormone receptor. Embo J, 16:4851-4858.

Grainger RJ \& Beggs JD (2005). Prp8 protein: at the heart of the spliceosome. RNA, 11:533557. 
Habelhah H, Takahashi S, Cho SG, Kadoya T, Watanabe T \& Ronai Z (2004). Ubiquitination and translocation of TRAF2 is required for activation of JNK but not of p38 or NFkappaB. Embo J, 23:322-332.

Hassink GC, Zhao B, Sompallae R, Altun M, Gastaldello S, Zinin NV, Masucci MG \& Lindsten K (2009). The ER-resident ubiquitin-specific protease 19 participates in the UPR and rescues ERAD substrates. EMBO Rep, 10:755-761.

Hassink GC, Slotman J, Oorschot V, van der Reijden BA, Monteferrario D, Noordermeer SM, van Kerkhof P, Klumperman J \& Strous GJ (2012). Identification of the ubiquitin ligase Triad1 as regulator of endosomal transport. Biol Open., on line doi: 10.1242/bio.2012778.

Hicke L \& Riezman H (1996). Ubiquitination of a yeast plasma membrane receptor signals its ligand-stimulated endocytosis. Cell, 84:277-287.

Huang DT, Ayrault O, Hunt HW, Taherbhoy AM, Duda DM, Scott DC, Borg LA, Neale G, Murray PJ, Roussel MF \& Schulman BA (2009). E2-RING expansion of the NEDD8 cascade confers specificity to cullin modification. Mol Cell, 33:483-495.

Iwai K \& Tokunaga F (2009). Linear polyubiquitination: a new regulator of NF-kappaB activation. EMBO Rep, 10:706-713.

Jovic M, Sharma M, Rahajeng J \& Caplan S (2010). The early endosome: a busy sorting station for proteins at the crossroads. Histol Histopathol, 25:99-112.

Kamsteeg EJ, Hendriks G, Boone M, Konings IB, Oorschot V, van der Sluijs P, Klumperman J \& Deen PM (2006). Short-chain ubiquitination mediates the regulated endocytosis of the aquaporin-2 water channel. Proc Natl Acad Sci U S A, 103:18344-18349.

Kirchhausen T (1999). Adaptors for clathrin-mediated traffic. Annu Rev Cell Devel Biol, 15:705-732.

Kumar KGS, Krolewski JJ \& Fuchs SY (2004). Phosphorylation and specific ubiquitin acceptor are required for ubiquitination and degradation of the IFNAR1 subunit of type I Interferon receptor. J. Biol. Chem., 279:46614-46620.

Lauwers E, Jacob C \& Andre B (2009). K63-linked ubiquitin chains as a specific signal for protein sorting into the MVB pathway. J Cell Biol, 185:493-502.

Li S, Zheng H, Mao AP, Zhong B, Li Y, Liu Y, Gao Y, Ran Y, Tien P \& Shu HB (2010). Regulation of virus-triggered signaling by OTUB1- and OTUB2-mediated deubiquitination of TRAF3 and TRAF6. J Biol Chem, 285:4291-4297.

Li Y, Suresh Kumar KG, Tang W, Spiegelman VS \& Fuchs SY (2004). Negative Regulation of Prolactin Receptor Stability and Signaling Mediated by SCF $\beta$ TrCP E3 Ubiquitin Ligase. Mol. Cell. Biol., 24:4038-4048.

Liu Q, Xu WG, Luo Y, Han FF, Yao XH, Yang TY, Zhang Y, Pi WF \& Guo XJ (2011). Cigarette smoke-induced skeletal muscle atrophy is associated with up-regulation of USP-19 via p38 and ERK MAPKs. J Cell Biochem, 112:2307-2316.

Lo Bianco C, Schneider BL, Bauer M, Sajadi A, Brice A, Iwatsubo T \& Aebischer P (2004). Lentiviral vector delivery of parkin prevents dopaminergic degeneration in an alphasynuclein rat model of Parkinson's disease. Proc Natl Acad Sci U S A, 101:17510-17515.

Loring GL, Christensen KC, Gerber SA \& Brenner C (2008). Yeast Chfr homologs retard cell cycle at G1 and G2/M via Ubc4 and Ubc13/Mms2-dependent ubiquitination. Cell Cycle, 7:96-105. 
Lu Y, Adegoke OA, Nepveu A, Nakayama KI, Bedard N, Cheng D, Peng J \& Wing SS (2009). USP19 deubiquitinating enzyme supports cell proliferation by stabilizing KPC1, a ubiquitin ligase for p27Kip1. Mol Cell Biol, 29:547-558.

Madshus IH \& Stang E (2009). Internalization and intracellular sorting of the EGF receptor: a model for understanding the mechanisms of receptor trafficking. J Cell Sci, 122:34333439 .

Marsh M \& McMahon HT (1999). The structural era of endocytosis. Science, 285:215-220.

Marteijn JA, van der Meer LT, Smit JJ, Noordermeer SM, Wissink W, Jansen P, Swarts HG, Hibbert RG, de Witte T, Sixma TK, Jansen JH \& van der Reijden BA (2009). The ubiquitin ligase Triad1 inhibits myelopoiesis through UbcH7 and Ubc13 interacting domains. Leukemia, 23:1480-1489.

Martin S, Nishimune A, Mellor JR \& Henley JM (2007). SUMOylation regulates kainatereceptor-mediated synaptic transmission. Nature, 447:321-325.

McNally T, Huang Q, Janis RS, Liu Z, Olejniczak ET \& Reilly RM (2003). Structural analysis of UBL5, a novel ubiquitin-like modifier. Protein Sci, 12:1562-1566.

Mei Y, Hahn AA, Hu S \& Yang X (2011). The USP19 deubiquitinase regulates the stability of c-IAP1 and c-IAP2. J Biol Chem, 286:35380-35387.

Meyer L, Deau B, Forejtnikova H, Dumenil D, Margottin-Goguet F, Lacombe C, Mayeux P \& Verdier $F$ (2007). $\beta$-TrCP mediates ubiquitination and degradation of the erythropoietin receptor and controls cell proliferation. Blood, 109:5215-5222.

Mishra SK, Ammon T, Popowicz GM, Krajewski M, Nagel RJ, Ares M, Jr., Holak TA \& Jentsch S (2011). Role of the ubiquitin-like protein Hub1 in splice-site usage and alternative splicing. Nature, 474:173-178.

Nakada S, Tai I, Panier S, Al-Hakim A, Iemura S, Juang YC, O'Donnell L, Kumakubo A, Munro M, Sicheri F, Gingras AC, Natsume T, Suda T \& Durocher D (2010). Noncanonical inhibition of DNA damage-dependent ubiquitination by OTUB1. Nature, 466:941-946.

Plans V, Scheper J, Soler M, Loukili N, Okano Y \& Thomson TM (2006). The RING finger protein RNF8 recruits UBC13 for lysine 63-based self polyubiquitylation. J Cell Biochem, 97:572-582.

Putters J, da Silva Almeida AC, van Kerkhof P, van Rossum AG, Gracanin A \& Strous GJ (2011a). Jak2 is a negative regulator of ubiquitin-dependent endocytosis of the growth hormone receptor. PLoS ONE, 6:e14676.

Putters J, Slotman JA, Gerlach JP \& Strous GJ (2011b). Specificity, location and function of betaTrCP isoforms and their splice variants. Cell Signal, 23:641-647.

Rahighi S, Ikeda F, Kawasaki M, Akutsu M, Suzuki N, Kato R, Kensche T, Uejima T, Bloor S, Komander D, Randow F, Wakatsuki S \& Dikic I (2009). Specific recognition of linear ubiquitin chains by NEMO is important for NF-kappaB activation. Cell, 136:1098-1109.

Rao Y, Ruckert C, Saenger W \& Haucke V (2011). The early steps of endocytosis: From cargo selection to membrane deformation. Eur J Cell Biol,

Row PE, Liu H, Hayes S, Welchman R, Charalabous P, Hofmann K, Clague MJ, Sanderson CM \& Urbe S (2007). The MIT domain of UBPY constitutes a CHMP binding and 
endosomal localization signal required for efficient epidermal growth factor receptor degradation. J Biol Chem, 282:30929-30937.

Schwartz AL \& Ciechanover A (2009). Targeting proteins for destruction by the ubiquitin system: implications for human pathobiology. Annu Rev Pharmacol Toxicol, 49:73-96.

Slotman JA, da Silva Almeida AC, Hassink GC, van de Ven RH, van Kerkhof P, Kuiken HJ \& Strous GJ (2012). UBC13 and COOH-terminus of HSP70 interacting protein (CHIP) are required for growth hormone receptor endocytosis. J Biol Chem, 287:15533-15543.

Soares L, Seroogy C, Skrenta H, Anandasabapathy N, Lovelace P, Chung CD, Engleman E \& Fathman CG (2004). Two isoforms of otubain 1 regulate T cell anergy via GRAIL. Nat Immunol, 5:45-54.

Soboleva TA \& Baker RT (2004). Deubiquitinating enzymes: their functions and substrate specificity. Curr Protein Pept Sci, 5:191-200.

Stanisic V, Malovannaya A, Qin J, Lonard DM \& O'Malley BW (2009). OTU Domaincontaining ubiquitin aldehyde-binding protein 1 (OTUB1) deubiquitinates estrogen receptor (ER) alpha and affects ERalpha transcriptional activity. J Biol Chem, 284:1613516145.

Staub O, Dho S, Henry PC, Correa J, Ishikawa T, McGlade J \& Torin D (1996). WW domains of NEDD4 bind to the proline-rich PY motifs in the epithelial Na channel deleted in Liddle's syndrome. Embo J, 15,:2371-2380.

Strous GJ, van Kerkhof P, Govers R, Ciechanover A \& Schwartz AL (1996). The ubiquitin conjugation system is required for ligand-induced endocytosis and degradation of the growth hormone receptor. Embo J, 15:3806-3812.

Strous GJ, van Kerkhof P, Govers R, Rotwein P \& Schwartz AL (1997). Growth hormoneinduced signal tranduction depends on an intact ubiquitin system. J Biol Chem, 272:4043.

Sun L, Deng L, Ea CK, Xia ZP \& Chen ZJ (2004). The TRAF6 ubiquitin ligase and TAK1 kinase mediate IKK activation by BCL10 and MALT1 in T lymphocytes. Mol Cell, 14:289-301.

Sundaram P, Pang Z, Miao M, Yu L \& Wing SS (2009). USP19-deubiquitinating enzyme regulates levels of major myofibrillar proteins in L6 muscle cells. Am J Physiol Endocrinol Metab, 297:E1283-1290.

Torres-Ramos CA, Prakash S \& Prakash L (2002). Requirement of RAD5 and MMS2 for postreplication repair of UV-damaged DNA in Saccharomyces cerevisiae. Mol Cell Biol, 22:2419-2426.

Ulrich HD \& Jentsch S (2000). Two RING finger proteins mediate cooperation between ubiquitin-conjugating enzymes in DNA repair. Embo J, 19:3388-3397.

van den Eijnden MJ, Lahaye LL \& Strous GJ (2006). Disulfide bonds determine growth hormone receptor folding, dimerisation and ligand binding. J Cell Sci, 119:3078-3086.

van der Bliek AM, Redelmeier TE, Damke H, Tisdale EJ, Meyerowitz EM \& Schmid SL (1993). Mutations in human dynamin block an intermediate stage in coated vesicle formation. J Cell Biol, 122:553-563. 
van Kerkhof P, Govers R, Alves dos Santos CM \& Strous GJ (2000). Endocytosis and degradation of the growth hormone receptor are proteasome-dependent. J Biol Chem, 275:1575-1580.

van Kerkhof P, Putters J \& Strous GJ (2007). The ubiquitin ligase SCF(betaTrCP) regulates the degradation of the growth hormone receptor. J Biol Chem, 282:20475-20483.

van Kerkhof P, Westgeest M, Hassink G \& Strous GJ (2011). SCF(TrCP) acts in endosomal sorting of the GH receptor. Exp Cell Res, 317:1071-1082.

Walder K, Ziv E, Kalman R, Whitecross K, Shafrir E, Zimmet P \& Collier GR (2002). Elevated hypothalamic beacon gene expression in Psammomys obesus prone to develop obesity and type 2 diabetes. Int J Obes Relat Metab Disord, 26:605-609.

Wang T, Yin L, Cooper EM, Lai MY, Dickey S, Pickart CM, Fushman D, Wilkinson KD, Cohen RE \& Wolberger C (2009). Evidence for bidentate substrate binding as the basis for the K48 linkage specificity of otubain 1. J Mol Biol, 386:1011-1023.

Weissman AM, Shabek N \& Ciechanover A (2011). The predator becomes the prey: regulating the ubiquitin system by ubiquitylation and degradation. Nat Rev Mol Cell Biol, 12:605-620.

Wooff J, Pastushok L, Hanna M, Fu Y \& Xiao W (2004). The TRAF6 RING finger domain mediates physical interaction with Ubc13. FEBS Lett, 566:229-233.

Wright MH, Berlin I \& Nash PD (2011). Regulation of endocytic sorting by ESCRT-DUBmediated deubiquitination. Cell Biochem Biophys, 60:39-46.

Wyatt D, Malik R, Vesecky AC \& Marchese A (2010). Small ubiquitin-like modifier modification of arrestin-3 regulates receptor trafficking. J Biol Chem, 286:3884-3893.

Zhang M, Windheim M, Roe SM, Peggie M, Cohen P, Prodromou C \& Pearl LH (2005). Chaperoned ubiquitylation-crystal structures of the CHIP U box E3 ubiquitin ligase and a CHIP-Ubc13-Uev1a complex. Mol Cell, 20:525-538.

Zou W, Papov V, Malakhova O, Kim KI, Dao C, Li J \& Zhang DE (2005). ISG15 modification of ubiquitin E2 Ubc13 disrupts its ability to form thioester bond with ubiquitin. Biochem Biophys Res Commun, 336:61-68. 